IP Periodica Polytechnica

Transportation Engineering

46(1), pp. 21-28, 2018

https://doi.org/10.3311/PPtr. 10113

Creative Commons Attribution (i)

RESEARCH ARTICLE

\section{Exposure to Traffic-related Air Pollution and the Onset of Childhood Asthma: A Review of the Literature and the Assement Methods Used}

\author{
Khair Jadaan $^{1,2}$, Haneen Khreis ${ }^{3}$, Ádám Török ${ }^{1 *}$
}

Received 06 October 2016; accepted 24 October 2016

\begin{abstract}
The overall objective of this study is to examine the literature investigating the associations between traffic-related air pollution (TRAP) and the incidence and prevalence of childhood asthma throughout a critical literature review The study examines and demonstrates the association between TRAP and childhood asthma, the literature associated with it, and the gaps in the current state of research. The exposure assessment methods currently in use in the literature are also overviewed and critically discussed for strengths and limitations.
\end{abstract}

\section{Keywords}

air pollution, childhood asthma, exposure assessment, exposure surrogates

\footnotetext{
${ }^{1}$ Department of Transport Technology and Economics, Faculty of Transportation Engineering and Vehicle Engineering, Budapest University of Technology and Economics, H-1521 Budapest, P.O.B. 91, Hungary

${ }^{2}$ Civil Engineering Department, University of Jordan, Amman, Jordan

${ }^{3}$ Institute for Transport Studies, University of Leeds, Leeds, UK

${ }^{*}$ Corresponding author, e-mail: torok.adam@mail.bme.hu
}

\section{Introduction}

Air pollution is a commonly recognized external cost of the use of motor vehicles (Barabas, 2013). In many urban areas nowadays, road traffic is the principal source of outdoor air pollution which has been recently linked to around 4 million global preventable deaths per annum (Solvang Jensen 1999; Colvile et al., 2001; European Environment Agency 2007; Health Effects Institute 2010; World Health Organization, 2014a). Despite many air quality improvements in recent decades, air pollution continues to pose a significant threat to human health and wellbeing worldwide (World Health Organization, 2006; Lim et al., 2013; Vidal, 2014). In particular, traffic-related air pollution is a key component to the ambient air pollution mix in present urban areas, and has been linked to a wide spectrum of global disease (Health Effects Institute, 2010).

In this study, the term traffic-related air pollution (TRAP) refers to the concentrations of primary and secondary air pollutants, elevated above background levels due to motor vehicles emissions. Traffic-related primary pollutants include carbon monoxide $(\mathrm{CO})$, carbon dioxide $(\mathrm{CO} 2)$, nitrogen oxides $\left(\mathrm{NO}_{\mathrm{x}}\right)$, ammonia $\left(\mathrm{NH}_{3}\right)$, particulate matter $(\mathrm{PM})$, and hydrocarbons (HC). Traffic-related secondary pollutants are those formed mainly by the various chemical reactions which take place in the atmosphere such as ozone $\left(\mathrm{O}_{3}\right)$, secondary particulates and secondary $\mathrm{NO}_{2}$.

In particular, recent research provides evidence indicating that significant associations exist between residential trafficrelated pollutant levels and asthma occurrences (Brauer et al., 2007; Salam et al., 2008).

With childhood asthma currently being a condition that has a profound impact on the quality of life for a large number of the population, especially in childhood; when individuals are most vulnerable, working towards establishing a clearer understanding of the interactions between a common exposure such as that to TRAP and the onset/ prevalence of the disease is clearly a priority. Such an understanding may be offering a partial explanation of the relatively rapid changes in prevalence, in times when traffic air pollution and certain fleets became more dominant. 
This study aims at examining the question of whether earlylife exposure to TRAP can cause asthma to develop in children and highlight the current limitations in the evidence base.

\section{Traffic-related air pollution and childhood asthma}

A sharp rise in the prevalence and incidence of asthma has been reported in many parts of the world, and particularly in the more developed and industrialized societies (Mutius, 1998; Beasley, 2004; Ferguson et al., 2004; Das, 2006; Anderson et al., 2007). These sharp increases in prevalence remain unexplained fully (Aubier, 2000; Bracken et al., 2002; London, 2007; Clark et al., 2010) and the prevailing views on the link between asthma and air pollution are conflicting. Although there is ample evidence that (traffic-related) air pollution can exacerbate asthma and trigger symptoms in persons who already have the condition, the question of whether it is an independent risk factor for the onset of asthma in children remains unresolved. Different studies that investigated this matter produce conflicting results making consensus difficult to reach (Gasana et al., 2012; Gowers et al., 2012; Lindgren et al., 2013). In these studies and in others, however, the effect of TRAP exposures was repeatedly shown as spatially heterogeneous, where it is mostly marked amongst those living within 50 to 75 meters of a busy road or a highway, whilst diminishing with increasing distance from the road (Venn et al., 2001; McConnell et al., 2006; Perez et al., 2012; Price et al., 2012). These observations are particularly relevant as TRAP is known to be spatially heterogeneous in space and time. Concentrations of common TRAP vary significantly over short distances as short as tens of meters.

In the investigated research articles, some authors reported an increase in the odds of incident asthma with increased exposure to different traffic-related air pollutants (Gauderman et al., 2002; Nicolai et al., 2003; Jerrett et al., 2008; Gehring et al., 2010), whilst others reported null association (Sahsuvaroglu et al., 2009; McConnell et al., 2010; Mölter et al., 2014). It is however possible that the different designs and exposure assessment methods in the different studies had an important role to play in these conflicting findings. The different studies employed different surrogates and/or air pollution measurements to represent exposure to TRAP levels and to then investigate the effects of this exposure. The collected studies differ in many ways as follows:

(1) the exposure assessment methods employed and the pollutants or traffic-related metrics investigated, (2) the definitions and ascertainment of asthma as an outcome, in (3) the study's design and (4) the study's sample's size; all of which are factors that can explain some of the variability and inconsistency of the results from different studies.

\section{Exposure assessment methods: strengths and limitations}

Because it is neither practical nor feasible to measure the personal exposure of individuals to TRAP at all points and at all times, different surrogates for the human exposure have been customarily employed in different epidemiological studies as a reasonable compromise for actual measurements. This part of the paper synthesizes the reviewed papers in reference to the exposure assessment methods employed whilst drawing attention to the main gaps found in the current state of research.

In the reviewed literature a wide variety of exposure metrics were employed to study the effects of air pollution on children's asthma. These exposure surrogates included:

- Proximity to a 'freeway' or a 'major road';

- Land use regression models;

- Dispersion models;

- Mathematical and statistical interpolation;

- Averaged measurements from fixed monitoring sites; and

- Hybrid models

Many of the exposure surrogates that were used in the literature cannot comprehensively represent the misaligned spatiotemporal nature of common vehicular air pollutants.

\subsection{Proximity to a 'freeway' or a 'major road'}

In the studies using this metric, subgroups of people living close to 'major' roads or the nearest freeway are compared to those who live at further distances. The distance to the road(s) of interest is typically objectively estimated using GIS. Although this exposure metric is intuitive and simple, it assumes a road of a certain type or size corresponds to a certain amount of traffic, and fails to take into account the compounded effects of proximity to multiple roads. As this metric cannot take meteorological conditions into account, it has a limited directional dependence, and automatically assumes that all pollutants disperse in a similar manner, which is inaccurate

Six out of the sixteen collected studies used this metric, either in isolation or alongside other criteria. In five of these studies, there was little evidence for an effect of major roadway proximity alone, where weak local and no associations between proximity to major roads and asthma were reported (Gauderman et al., 2005; McConnell et al., 2010). The exception of this was in the study by Gauderman et al. (2005) where the residential distance from the nearest freeway was the distance investigated. In their study, simple distance to a freeway was as strongly associated with a life history of asthma as was measured ambient $\mathrm{NO}_{2}$. On the other hand, Venn and co-workers found that the increased odds of childhood wheeze occurrence in relation to road proximity were local and only visible within 150 meters from the road. Similarly, McConnell et al. (2006) and follow-up work in McConnell et al. (2010) showed high risks of asthma in children residing at less than 75 meters from a major road, with susceptibility found to 
have significantly increased in long-term residents with no parental history of asthma. The authors also observed that these risks decreased to reach background rates at 150-200 meters from the road as illustrated in Fig .1. Finally, Lindgren et al. (2013) and Sahsuvaroglu et al. (2009) found no association between this exposure metric and the occurrence of asthma.

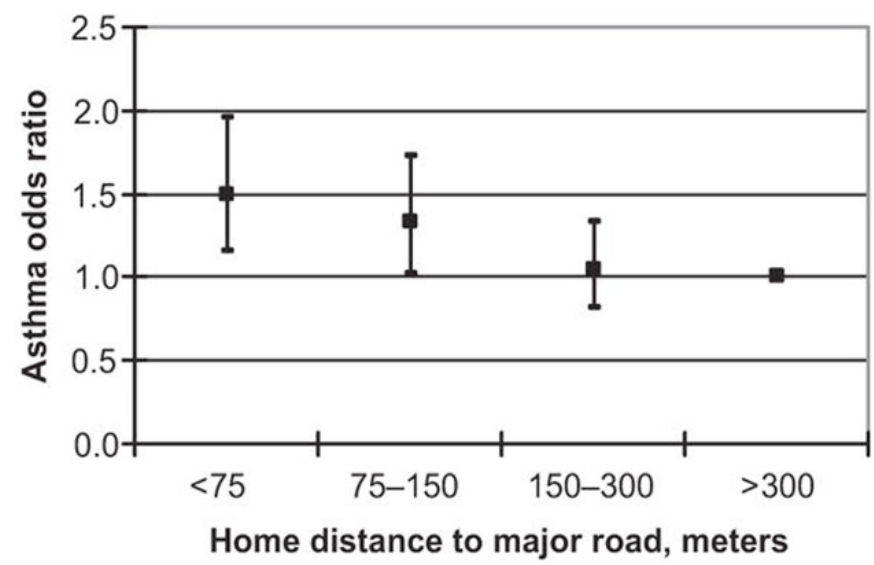

Fig. 1 Traffic proximity and risk of asthma in the CHS source: McConnell et al., 2006 adapted from (Gilliland, 2009)

These weak, localized and absent effects can be possibly explained by one of three reasons. Firstly, an effect of the exposure could be absent. Secondly, an existing effect may have been concealed because of the crudity of the exposure metric employed. Proximity to major roads assumes that a classified or a numbered road corresponds to a certain amount of traffic, usually with a relatively wide range. It furthermore lacks important information on traffic density, the vehicular mix and fails to take into account the completely different nature of dispersion for different pollutants. The compounded influence of proximity to other roads is also often neglected when using such a metric (Brook, 2012), and the unusual concentrations of traffic-related air pollution in street canyons cannot be accounted for. Finally, studies finding a localized effect when using this metric may have implications on which pollutant(s) is more likely to be responsible for the observed effect(s), as the composition of fresh vehicular exhaust is different than that of the aging exhaust, and the different dispersion manners for different pollutants can cause them to vary significantly in concentrations between the roadside and further. Here, ultra-fine particles are pollutants which attracts attention as their concentrations are relatively high nearby roadsides, with very steep decreases with increasing distances from the source.

\subsection{Land use regression models}

Land Use Regression models (LUR) were the second exposure metric that has been used in four out of the sixteen collected studies and in other recent major air pollution and health research projects such as the European Study of Cohorts for Air Pollution Effects (ESCAPE) (Eeftens et al., 2012; Beelen et al., 2013).
LUR models seek to predict air pollution concentrations at sites of interest based on previous monitoring data and the surrounding land use and traffic characteristics (Jerrett et al., 2004). LUR have recently gained considerable interest and have become more widely used to estimate the exposure of cohort studies participants to air pollution (Ryan and LeMasters, 2007). This increased popularity of this method is possibly due to the facts that LUR models require relatively little time to establish, input data that is easy to collate, have relatively low costs and have the capability of showing changes in the spatial patterns of pollutants over large distances.

Although LUR have the capacity to show changes in the spatial patterns of pollutants, they can only reflect the predictors that were used in establishing the model, suffer from varying uncertainties amongst different pollutants (Brook, 2012), and the true contribution of traffic to the regression is not always known or reported (Health Effects Institute, 2010). Similarly, to the 'proximity to major roads' metric, LUR models cannot take into account the effects of terrain, topography and meteorological conditions on air pollution concentrations which can greatly influence exposure experiences. As the models are also based on actual measurements made for the pollutants of interest, the model's outputs are sensitive to the locations of the sampling sites, and to a lesser extent, the number of air sampling sites (Ryan and LeMasters, 2007). Finally, as the used predictors can have a high contribution to the final regression, the meaningfulness of these predictors is an essential point, especially when moving to study areas with much different land use and topography (Jerrett et al., 2004).

In work undertaken by Gehring et al. (2010), the authors used predictor variables that are related to motor vehicles traffic as the model's predictors, such as the traffic intensity in the area of investigation and the population density which can have a role in driving trips from and to a zone. On the other hand, Sahsuvaroglu et al. (2009) used seven predictors to set up their model as follows: traffic density, open land use within 500 meters, industrial land use within 200 meters, presence of a highway within 50 meters, presence within 1000 meters from downtown industrial core, presence downwind from a highway, and distance to the lake. Work by Clark et al., 2010 relied on LUR models developed by Henderson and co-workers who used fifty-five variables describing each sampling site as predictors of the LUR model in a GIS (Henderson et al., 2007). Even with this high number of predictive variables used for the models development, adjusted R2 values ranged from 0.39 to 0.62 . Finally, the LUR models developed in work by Mölter et al. (2014) employed eight covariates including traffic intensity, emissions, land use and physical geography as predictor variables for the final models. The $\mathrm{R}^{2}$ values of their models ranged from 0.56 to 0.86 .

In all of these studies it could be argued that these predictors are still not allowing for some important factors that are of vital influence on the traffic-PM and traffic- $\mathrm{NO}_{2}$ concentrations, 
which these models predicted. Some of these factors include the vehicular mix and fleet's composition and speeds, the emission factors for the main classes of the vehicles composing the fleet and the street characteristics and meteorological conditions which can greatly impact the dispersion processes.

As for different pollutants' uncertainties, good agreement between the long-term measured and predicted $\mathrm{NO}_{2}$ and $\mathrm{PM}_{2.5}$ was shown in LUR models (Montagne et al., 2013), even from nitrogen dioxide samples collected 12 years apart (Cesaroni et al., 2012). It is important to note though that agreement studies are usually based on averaged measurements similar to those initially used to develop the LUR models, and averaged measurements have their own inherent limitation in assessing the exposure. There is also another important question of whether NO2, the pollutant most studies by LUR models, is a reasonable proxy for traffic-related air pollution.

\subsection{Dispersion modelling}

Dispersion modelling is a technique which involves the construction of a dynamic model that utilizes emission rates from different sources such as motor vehicles, alongside meteorology and boundary layer conditions to simulate the dispersion process, and to predict the following ambient concentrations of air pollutants (Briggs et al., 1997; Health Effects Institute, 2010). Estimates derived from dispersion models are continuous exposure metrics, which incorporate traffic flows, meteorology and atmospheric chemistry when making the final ambient pollution levels predictions. The models generally rely on Gaussian plume equations to predict the pollution concentrations, in which steady-state meteorological conditions are assumed. Gaussian plume models also assume that there are no chemical or removal processes taking place (Vardoulakis et al., 2003).

In recent years, dispersion models have been jointly used with GIS. The models can make air pollution predictions for relatively large areas, and can assess severe episodic short-term and long-term exposures at receptor points of interest. The outputs of dispersion models have the highest temporal and spatial resolution in relation to all other exposure metrics found in use in the reviewed literature. Furthermore, many of the commonly used dispersion models such as INDIC AIRVIRO and Atmospheric Dispersion Modelling System (ADMS) can also take into account a street canyon contribution in the most polluted segments using their built-in street canyon model, namely; the Danish Operational Street Pollution Model (OSPM).

Five out of the sixteen collected studies were found to have used dispersion models to assess the exposure, either in isolation (Nordling et al., 2008; Gruzieva et al., 2013), or alongside other metrics (Gauderman et al., 2005; McConnell et al., 2010; Lindgren et al., 2013). In these studies, the use of dispersion models to assess the exposure is advantageous over the previously described metrics as it allows a more accurate assessment of the impact of variable sources' emissions loads on ambient air quality, and provides outputs that are characterized by a relatively high temporal and spatial resolution. However, although such models can better reflect the different dispersion manner for different pollutants and take into account meteorology, emission rates and some atmospheric chemistry, their output's quality is highly dependent on that of the input. The validity of the dispersion modelling results is at the mercy of the emission factors used to calculate inputted emission rates (Barrat, 2013). Emission factors and consequently emissions' estimates remain an essential source of uncertainty in dispersion modelling; especially when considering the real world divergence of the $\mathrm{NO}_{\mathrm{x}}$ emission factors for certain growing sub fleets such as diesel cars. The models must therefore be calibrated correctly in order to realize their advantages (Health Effects Institute, 2010), and cross validated with monitoring data where possible to test their performances.

\subsection{Interpolation techniques}

Alongside dispersion models, interpolation techniques can also be used to map and predict ambient air pollution concentrations. Interpolation models can assign pollution concentrations to locations of interest based on some surrounding measured values, and various underlying mathematical formulas or statistical models (ERSI, 2008).

The three most commonly used interpolation tools in air pollution and health research are the Inverse Distance Weighting (IDW), the Splines and Kriging (Ranade et al., ND). These three tools were used in the study by Sahsuvaroglu and co-workers to assess the exposure, where no associations were found with incident asthma. Their results may be explained by either the absence of the effect, or the by inherent limitations of these metrics which are described next. The Spline tool works by fitting a mathematical function across all input data values to create a prediction surface. Spline works best for surfaces that vary mildly (Ranade et al., ND), and does not perform well when large variations along the surface can occur within short distances (U.S. Environmental Protection Agency, 2004). As previously discussed, concentrations of common vehicular pollutants are spatially misaligned and can significantly fluctuate even over no more than a few tens of meters (Briggs et al., 1997; Sharma et al., 2005; Bell, 2009), therefore, results emerging from the use of this method should be treated with caution.

On the other hand, the IDW is a simple deterministic interpolation method based on the principle that sample values closer to the prediction location have more influence on prediction value than sample values which are further away. The main shortcoming of this approach is its "bull's eye" effect where the highest values will be assigned to points that are near the sampled locations (Ranade et al., ND). The other problem with the IDW tool is that the range of the predicted values is always constrained by the range of the measured ones as determined by its highest and lowest sampled values (U.S. Environmental 
Protection Agency, 2004). This would become an issue when no measurements were made within a certain area(s); arguably causing a biased spatial heterogeneity when investigating the cause and effect, and an existing pattern is likely to be concealed where no representative measurements were made.

Finally, kriging is the geostatistical technique most commonly used in the air pollution field (Jerrett et al., 2004). Kriging uses a tool known as the semivariogram for making predictions. The semivariogram model and its underlying statistical assumptions are an ad hoc approach, especially for making predictions of air pollution surfaces. This was discussed in details elsewhere, after kriging in GIS was previously used in a case study in Sheffield.

\subsection{Averaged measurements}

Averaged measurements of different pollutants from continuous regulatory monitoring stations or from fixed sited measurement equipment such as $\mathrm{NO}_{2}$ Palmes tubes were another exposure surrogate used in the literature reviewed.

Three studies out of the sixteen collected studies used continuous measurements obtained from fixed regulatory air quality monitoring stations to reflect the population exposure to traffic-related air pollutants (Hwang et al., 2005; Clark et al., 2010; McConnell et al., 2010). Four other studies have undertaken their own measurements campaigns and used averaged and temporally adjusted measurements to reflect the populations' exposure, either in isolation or alongside other metrics (Brauer et al., 2002; Nicolai et al., 2003; Gauderman et al., 2005; Jerrett et al., 2008,).

Although continuous monitoring stations are cost effective and have a very high and continuous temporal resolution, they have important shortcomings. Because of the distinct spatially heterogeneous nature of TRAP, the fact that air quality monitoring stations cannot be present at all locations of interest, and that their locations are usually based on regulatory rather than scientific purposes (Bell, 2009), this approach is problematic when assessing this exposure and can lead to misclassifications. Problems can arise when using this method either because the exposure can be overestimated when considering populations residing in industrialized areas (Mölter et al., 2014), or it can be underestimated when specifically investigating TRAP. Indeed, fixed monitoring stations were found to significantly underestimate the exposure concentration levels experienced by individuals exposed in urban environments, especially when in or near transport microenvironments (Kaur et al., 2007). Moreover, the use of monitoring stations to assign the exposure for large populations will most certainly conceal people's differences because of a mismatch between the data used to estimate exposure and the actual subjects' locations.

Secondly, because of the temporally heterogeneous nature of traffic-related air pollution, averaged measurements from fixed sited measurement equipment, even if spatially well-distributed, will fail to pick up the variations in pollutants concentrations in real time. It is also likely to underestimate occasional exposure as severe episodic pollution levels can be concealed in the averaged values if they don't occur often enough.

\subsection{Hybrid models}

Hybrid models were also employed in some studies. These models are largely based on the above mentioned basic exposure metrics combined with each other or with other measurements such as vehicles counts, traffic flows etc. The limitations of such metrics can be explained by the inherent limitations of its composing elements.

Against this background, it is clear that the development of models to assess exposure to TRAP is a priority area for future research. Evaluating the health effects of exposure to TRAP is subtle to the method of the exposure estimation. Many of the exposure surrogates that were used in the literature are crude, and do not relate well to the misaligned spatio-temporal nature of common vehicular air pollutants.

\section{Early-life exposure}

In the vast majority of the studies confirming a link between traffic-related air pollution and the onset of asthma, the effects are stronger and highlighted in the early years of the child's life. Some of the papers reviewed demonstrate that a critical exposure window could exist for children before their third year and whilst they are still in utero (Brauer et al., 2002; Gauderman et al., 2005; Nordling et al., 2008; Clark et al., 2010; Gruzieva et al., 2013). These findings are in line with other research, showing that exposure to air pollution before three years of age can have long-term consequences on the lung and the lung development and suggesting that the timing of the exposure is possibly a crucial factor in the inception of asthma.

\section{Identified critical pollutants}

In line with growing evidence, no safe threshold for TRAP can be drawn from the reviewed studies, which below zero risk would occur. Numerous studies are demonstrating that the effects of air pollution on the respiratory health are evident, even at concentration levels that are officially considered safe. For instance, after adjusting to potential confounders, a 5 parts per billion increase in the average $\mathrm{NO}_{2}$ exposure during the first year of a child's life was found to be associated with a 1.17 odds ratio for physician-diagnosed asthma (Nishimura et al., 2013).

From the pool of pollutants that were investigated throughout the collected studies, exposure to $\mathrm{NO}_{2}$ showed the most consistent and significant associations (described by the odds ratios) with the incidence and prevalence of childhood asthma, followed by exposure to $\mathrm{PM}_{2.5}$ and $\mathrm{PM}_{10}$. Other unregulated pollutants such as NH3 and UFPs -with the latter being arguably most toxic because of its physiochemical properties were not described in any of the studies. 


\section{Conclusion and Future Work}

There has been increasing evidence to suggest that TRAP exposures are associated with the onset and prevalence of childhood asthma. However, an analysis of the literature suggests that the development of more refined exposure models to assess exposure to TRAP should be a priority area for future research.

Evaluating the health effects of exposure to TRAP is affected by the method of the exposure estimation and many of the exposure surrogates that were used in the literature continue to be a limitation. More refined exposure models are needed, and will arguably produce the most robust associations when investigating the potential health effects of TRAP. No study was found to assess the effect of repeated short-term severe exposures and future studies may gain new insight from investigating the effect exposure to episodic severe concentrations of TRAP, alongside continual long-term exposures. At present, there are no available studies on the particular effect of longterm exposure, or short-term repeated exposures to ultra-fine particles (UFP) on the incidence or the prevalence of asthma in children. This is in part a result of the high costs and logistic difficulties in measuring levels of UFPs for large populations on the one hand. On the other hand, an incomplete understanding of the sources and vehicles' emissions trends of UFPs contribute to additional methodological difficulties when trying to model and predict UFPs levels.

Current dispersion models are not designed to predict the UFPs ambient concentrations, especially when associated with traffic sources. Recent research, however, demonstrates that UFPs warrant special examination in the context of asthma and other respiratory disease, and that it is the fraction of particulate matter where most of the mixture's toxicity seems to reside. Future studies could benefit from investigating associations with UFPs which can be modelled based on other explanatory variable at the local scale such as traffic NOx. As it stands, the impact of TRAP on asthma prevalence is potentially significant due to the large number of children exposed. Policy decisionmaking should address these impacts by reducing childhood exposures through relevant transport and land use policies.

\section{Acknowledgement}

Authors are grateful for the support of János Bólyai Scholarship of Hungarian Academy of Sciences.

\section{References}

Anderson, H. R., Gupta, R., Strachan, D. P., Limb, E. S. (2007). 50 years of asthma. UK trends from 1955 to 2004. Thorax. 62(1), pp. 85-90.

Aubier, M. (2000). Atmospheric pollution and allergic asthma. Pollution atmospherique et asthma allergique. Revue des maladies respiratoires. 17(1 BIS), pp. 159-165. (in French)

Barrat, B. (2013). Low Emission Zones and other Traffic Reduction Measures, HEI Annual Conference. [Online]. Available from: http://www.healtheffects.org/Slides/AnnConf2013/Barratt-MonPM.pdf [Accessed: 15th April 2013].

Barabás, I. (2013). Predicting the temperature dependent density of biodieseldiesel-bioethanol blends. Fuel. 109, pp. 563-574.

https://doi.org/10.1016/j.fuel.2013.03.001

Beasley, R. (2004). The Global Burden of Asthma Report, Global Initiative for Asthma (GINA), 1, Global Initiative for Asthma.

Beelen, R., Hoek, G., Vienneau, D., Eeftens, M., Dimakopoulou, K., Pedeli, X., Tsai, M.-Y., Künzli, N., Schikowski, T., Marcon, A. (2013). Development of $\mathrm{NO} 2$ and $\mathrm{NO} x$ land use regression models for estimating air pollution exposure in 36 study areas in Europe-The ESCAPE project. Atmospheric Environment. 72, pp. 10-23. https://doi.org/10.1016/j.atmosenv.2013.02.037

Bell, L. M. (2009). Critical Issues of Exposure Assessment for Human Health Studies of Air Pollution. [Online]. Available from: http://www.powershow.com/view4/575b8b-Y2E1Z/Critical_Issues_of_Exposure_Assessment_for_Human_Health_Studies_of_Air_Pollution_powerpoint_ppt presentation [Accessed: 21th August 2014].

Bracken, M. B., Belanger, K., Cookson, W. O., Triche, E., Christiani, D. C., Leaderer, B. P. (2002). Genetic and perinatal risk factors for asthma onset and severity. a review and theoretical analysis. Epidemiologic Reviews. 24(2), pp. 176-189

Brauer M, Hoek G, Smit, H. A., de Jongste, J. C., Gernitsen, J., Postma, D. S., Kerkhof, M., Brunekreet, B.(2007). Air pollution and the development of asthma, allergy and infections in a birth cohort. European Respiration Journal. 29, pp. 879-888. https://doi.org/10.1183/09031936.00083406

Brauer, M., Hoek, G., Van Vliet, P., Meliefste, K., Fischer, P. H., Wijga, A., Koopman, L. P., Neijens, H. J., Gerritsen, J., Kerkhof, M. (2002). Air pollution from traffic and the development of respiratory infections and asthmatic and allergic symptoms in children. American Journal of Respiratory and Critical Care Medicine. 166(8), pp. 1092-1098. https://doi.org/10.1164/rccm.200108-007OC

Briggs, D. J., Collins, S., Elliott, P., Fischer, P., Kingham, S., Lebret, E., Pryl, K., van Reeuwijk, H., Smallbone, K., Van Der Veen, A. (1997). Mapping urban air pollution using GIS. a regression-based approach. International Journal of Geographical Information Science. 11(7), pp. 699-718. https://doi.org/10.1080/136588197242158

Brook, J. R. (2012). Estimating exposure to traffic-related air pollution. In: Health Effects Institute Annual Conference, Chicago, Illinois, April 15-17, 2012.

Cesaroni, G., Porta, D., Badaloni, C., Stafoggia, M., Eeftens, M., Meliefste, K., Forastiere, F. (2012). Nitrogen dioxide levels estimated from land use regression models several years apart and association with mortality in a large cohort study. Environmental Health. 11(1), pp. 48.

https://doi.org/10.1186/1476-069X-11-48

Clark, N. A., Demers, P. A., Karr, C. J., Koehoorn, M., Lencar, C., Tamburic, L., Brauer, M. (2010). Effect of early life exposure to air pollution on development of childhood asthma. Environmental Health Perspectives. 118(2), pp. 284-290. https://doi.org/10.1289/ehp.0900916

Colvile, R., Hutchinson, E., Mindell, J., Warren, R. (2001). The transport sector as a source of air pollution. Atmospheric Environment. 35(9), pp. 1537 1565. https://doi.org/10.1016/S1352-2310(00)00551-3 
Das, A. (2006). Asthma Crisis in Low-Income Communities of Color. Using the Law as a Tool for Promoting Public Health. Review of Law and Social Change. 31(2), pp. 273-314.

Eeftens, M., Beelen, R., de Hoogh, K., Bellander, T., Cesaroni, G., Cirach, M., Declercq, C., Dedele, A., Dons, E., de Nazelle, A. (2012). Development of land use regression models for $\mathrm{PM}_{25}, \mathrm{PM}_{25}$ absorbance, $\mathrm{PM}_{10}$ and PMcoarse in 20 European study areas; results of the ESCAPE project. Environmental Science \& Technology. 46(20), pp. 11195-11205. https://doi.org/10.1021/es301948k

ERSI (2008). An overview of the Interpolation tools. [Online]. Available from: http://webhelp.esri.com/arcgisdesktop/9.2/index.cfm?TopicName=An_ overview_of_the_Interpolation_tools [Accessed: 3rd January 2008].

European Environment Agency, EEA. (2007). Transport Contribution to Air Quality. [Online]. Available from: http://www.eea.europa.eu/data-andmaps/indicators/transport-contribution-to-air-quality-3 [Accessed: 18th January 2014].

Ferguson, E. C., Maheswaran, R., Daly, M. (2004). Road-traffic pollution and asthma-using modelled exposure assessment for routine public health surveillance. International Journal of Health Geographics. 3(1), pp. 24-31. https://doi.org/10.1186/1476-072X-3-24

Gasana, J., Dillikar, D., Mendy, A., Forno, E., Ramos Vieira, E. (2012). Motor vehicle air pollution and asthma in children. a meta-analysis. Environmental Research. 117, pp. 36-45.

https://doi.org/10.1016/j.envres.2012.05.001

Gauderman, W. J., Avol, E., Lurmann, F., Kuenzli, N., Gilliland, F., Peters, J., McConnell, R. (2005). Childhood asthma and exposure to traffic and nitrogen dioxide. Epidemiology. 16(6), pp. 737-743.

Gauderman, W. J., Gilliland, G. F., Vora, H., Avol, E., Stram, D., McConnell, R., Thomas, D., Lurmann, F., Margolis, H. G., Rappaport, E. B. (2002). Association between air pollution and lung function growth in southern California children. results from a second cohort. American Journal of Respiratory and Critical Care Medicine. 166(1), pp. 76-84. https://doi.org/10.1164/rcem.2111021

Gehring, U., Wijga, A. H., Brauer, M., Fischer, P., de Jongste, J. C., Kerkhof, M., Oldenwening, M., Smit, H. A., Brunekreef, B. (2010). Traffic-related air pollution and the development of asthma and allergies during the first 8 years of life. American Journal of Respiratory and Critical Care Medicine. 181(6), pp. 596-603. https://doi.org/10.1164/rccm.200906-08580C

Gilliland, F. D. (2009). Outdoor air pollution, genetic susceptibility, and asthma management opportunities for intervention to reduce the burden of asthma. Pediatrics. 123(Supplement 3), pp. S168-S173. https://doi.org/10.1542/peds.2008-2233G

Gowers, A. M., Cullinan, P., Ayres, J. G., Anderson, H., Strachan, D. P., Holgate, S. T., Mills, I. C., Maynard, R. L. (2012). Does outdoor air pollution induce new cases of asthma? Biological plausibility and evidence; a review. Respirology. 17(6), pp. 887-898. https://doi.org/10.1111/j.1440-1843.2012.02195.x

Gruzieva, O., Bergström, A., Hulchiy, O., Kull, I., Lind, T., Melén, E., Moskalenko, V., Pershagen, G., Bellander, T. (2013). Exposure to air pollution from traffic and childhood asthma until 12 years of age. Epidemiology. 24(1), pp. 54-61.

https://doi.org/10.1097/EDE.0b013e318276c1ea

Health Effects Institute, H. E. I. (2010). Traffic-related air pollution. a critical review of the literature on emissions, exposure, and health effects. Health Effects Institute. URL: https://www.healtheffects.org/publication/traffic-related-air-pollution-critical-review-literature-emissions-exposure-and-health

Hwang, B.-F., Lee, Y.-L., Lin, Y.-C., Jaakkola, J. J., Guo, Y. (2005). Traffic related air pollution as a determinant of asthma among Taiwanese school children. Thorax. 60(6), pp. 467-473.
Jerrett, M., Arain, A., Kanaroglou, P., Beckerman, B., Potoglou, D., Sahsuvaroglu, T., Morrison, J., Giovis, C. (2004). A review and evaluation of intraurban air pollution exposure models. Journal of Exposure Science and Environmental Epidemiology. 15(2), pp. 185-204.

Jerrett, M., Shankardass, K., Berhane, K., Gauderman, W. J., Künzli, N., Avol, E., Gilliland, F., Lurmann, F., Molitor, J. N., Molitor, J. T. (2008). Traffic-related air pollution and asthma onset in children. a prospective cohort study with individual exposure measurement. Environmental Health Perspectives. 116(10), pp. 1433-1438.

https://doi.org/10.1289/ehp.10968

Kaur, S., Nieuwenhuijsen, M. J., Colvile, R. N. (2007). Fine particulate matter and carbon monoxide exposure concentrations in urban street transport microenvironments. Atmospheric Environment. 41(23), pp. 4781-4810. https://doi.org/10.1016/j.atmosenv.2007.02.002

Lim, S. S., Vos, T., Flaxman, A. D., Danaei, G., Shibuya, K., Adair-Rohani, H., Amann, M., Anderson, H. R., Andrews, K. G., Aryee, M. (2013). A comparative risk assessment of burden of disease and injury attributable to 67 risk factors and risk factor clusters in 21 regions, 1990-2010. a systematic analysis for the Global Burden of Disease Study 2010. The Lancet. 380(9859), pp. 2224-2260. https://doi.org/10.1016/S0140-6736(12)61766-8

Lindgren, A., Stroh, E., Björk, J., Jakobsson, K. (2013). Asthma incidence in children growing up close to traffic: a registry-based birth cohort. Environmental Health. 12(1), pp. 91-102.

https://doi.org/10.1186/1476-069X-12-91

London, S. J. (2007) Gene-air pollution interactions in asthma, Proceedings of the American Thoracic Society. 4(3), pp. 217-220.

McConnell, R., Berhane, K., Yao, L., Jerrett, M., Lurmann, F., Gilliland, F., Künzli, N., Gauderman, J., Avol, E., Thomas, D. (2006). Traffic, susceptibility, and childhood asthma. Environmental Health Perspectives. 114(5), pp. 766-772.

McConnell, R., Islam, T., Shankardass, K., Jerrett, M., Lurmann, F., Gilliland, F., Gauderman, J. (2010). Childhood incident asthma and traffic-related air pollution at home and school. Environmental Health Perspectives. 118(7), pp. 1021-1026. https://doi.org/10.1289/ehp.0901232

Mölter, A., Agius, R., de Vocht, F., Lindley, S., Gerrard, W., Custovic, A., Simpson, A. (2014). Effects of long-term exposure to PM10 and NO2 on asthma and wheeze in a prospective birth cohort. Journal of Epidemiology and Community Health. 68(1), pp. 21-28. https://doi.org/10.1136/jech-2013-202681

Montagne, D., Hoek, G., Nieuwenhuijsen, M., Lanki, T., Pennanen, A., Portella, M., Meliefste, K., Eeftens, M., Yli-Tuomi, T., Cirach, M. (2013). Agreement of Land Use Regression models with personal exposure measurements of particulate matter and nitrogen oxides air pollution. Environmental Science \& Technology. 47(15), pp. 8523-8531. https://doi.org/10.1021/es400920a

Mutius, V. (1998). The rising trends in asthma and allergic disease. Clinical \& Experimental Allergy. 28(5), pp. 45-49.

Nicolai, T., Carr, D., Weiland, S., Duhme, H., Von Ehrenstein, O., Wagner, C., Von Mutius, E. (2003). Urban traffic and pollutant exposure related to respiratory outcomes and atopy in a large sample of children. European Respiratory Journal. 21(6), pp. 956-963.

Nishimura, K. K., Galanter, J. M., Roth, L. A., Oh, S. S., Thakur, N., Nguyen, E. A., Thyne, S., Farber, H. J., Serebrisky, D., Kumar, R. (2013). Early Life Air Pollution and Asthma Risk in Minority Children. The GALA II \& SAGE II Studies. American Journal of Respiratory and Critical care Medicine. 188(3), pp. 309-318. https://doi.org/10.1164/rccm.201302-0264OC 
Nordling, E., Berglind, N., Melen, E., Emenius, G., Hallberg, J., Nyberg, F., Pershagen, G., Svartengren, M., Wickman, M., Bellander, T. (2008). Traffic-related air pollution and childhood respiratory symptoms, function and allergies. Epidemiology. 19(3), pp. 401-408. https://doi.org/10.1097/EDE.0b013e31816a1ce3

Perez, L., Lurmann, F., Wilson, J., Pastor, M., Brandt, S. J., Künzli, N., McConnell, R. (2012). Near-Roadway Pollution and Childhood Asthma. Implications for Developing "Win-Win" Compact Urban Development and Clean Vehicle Strategies. Environmental Health Perspectives. 120(11), pp. 1619-1626.

Price, K., Plante, C., Goudreau, S., Boldo, E. I. P., Perron, S., Smargiassi, A. (2012). Risk of childhood asthma prevalence attributable to residential proximity to major roads in Montreal, Canada. Canadian Journal of Public Health. 103(2), pp. 113-118.

Ranade, P., Irmak, A., Maidment, D. (ND) Geostatistical Analyst. [Online]. Available from: http://www.caee.utexas.edu/prof/maidment/giswr2008/ geostat/ExGeostat.doc [Accessed: 16th April 2014].

Ryan, P. H., LeMasters, G. K. (2007). A review of land-use regression models for characterizing intraurban air pollution exposure. Inhalation Toxicology. 19(S1). pp. 127-133. https://dx.doi.org/10.1080\%2F08958370701495998

Sahsuvaroglu, T., Jerrett, M., Sears, M. R., McConnell, R., Finkelstein, N., Arain, A., Newbold, B., Burnett, R. (2009). Spatial analysis of air pollution and childhood asthma in Hamilton, Canada: comparing exposure methods in sensitive subgroups. Environmental Health. 8(1), p. 14.

Salam M T, Islam T, Gilliland F. (2008). Recent evidence for adverse effects of residential proximity to traffic sources on asthma. Current Opinion in Pulmonary Medicine. 14(1), pp. 3-8. https://doi.org/10.1097/MCP.0b013e3282f1987a
Sharma, N., Chaudhry, K., Rao, C. C. (2005). Air pollution dispersion studies through environmental wind tunnel (EWT) investigations: A review. Journal of Scientific and Industrial Research. 64(8), pp. 549-559.

Solvang Jensen, S. (1999). A geographic approach to modelling human exposure to traffic air pollution using GIS, Ministry of Environment and Energy, National Environmental Research Institute.

U.S. Environmental Protection Agency, E. P. A. (2004). Developing Spatially Interpolated. Surfaces and Estimating Uncertainty. [Online]. Available from: http://www.epa.gov/airtrends/specialstudies/dsisurfaces.pdf [Accessed: 22nd September 2014].

Vardoulakis, S., Fisher, B. E., Pericleous, K., Gonzalez-Flesca, N. (2003). Modelling air quality in street canyons: a review. Atmospheric Environment. 37(2), pp. 155-182. https://doi.org/10.1016/S1352-2310(02)00857-9

Venn, A. J., Lewis, S. A., Cooper, M., Hubbard, R., Britton, J. (2001). Living near a main road and the risk of wheezing illness in children. American Journal of Respiratory and Critical Care Medicine. 164(12), pp. 2177-2180. https://doi.org/10.1164/ajrccm.164.12.2106126

Vidal, J. (2014). WHO. air pollution is single biggest environmental health risk. [Online]. Available from: https://www.theguardian.com/environment/2014/mar/25/air-pollution-single-biggest-environmental-health-risk-who [Accessed: 25th March 2014].

World Health Organization, W. H. O. (2006). Air quality guidelines for particulate matter, ozone, nitrogen dioxide and sulfur dioxide. Global update 2005, Geneva. World Health Organization.

World Health Organization, W. H. O. (2014). Burden of Disease from Air Pollution for 2012. Summary of Results,, Geneva. World Health Organization. 